\title{
The Composition of the Fungal and Oomycete Microbiome of Rhododendron Roots Under Varying Growth Conditions, Nurseries, and Cultivars
}

\author{
Z. S. L. Foster, ${ }^{1}$ J. E. Weiland, ${ }^{2}$ C. F. Scagel, ${ }^{2}$ and N. J. Grünwald ${ }^{2, \dagger}$ \\ ${ }^{1}$ Department of Botany and Plant Pathology, Oregon State University, Corvallis, OR \\ ${ }^{2}$ Horticultural Crops Research Unit, U.S. Department of Agriculture-Agricultural Research Service, Corvallis, OR \\ Accepted for publication 17 January 2020.
}

\section{ABSTRACT}

The microbiome of agricultural crops influences processes such as nutrient absorption, drought stress, and susceptibility to pathogens. Interactions between a plant's genotype and its environment influence the composition of the microbiome, but these interactions are not well understood. We compared how the fungal and oomycete microbiomes of rhododendrons from Oregon nurseries differed among cultivars, growth conditions, and nurseries. Roots were sampled from randomly selected container and field-grown plants of three cultivars of rhododendron at four nurseries. The internal transcribed spacer 1 (ITS1) barcode was sequenced with the Illumina MiSeq using two sets of primers specific to fungi and oomycetes, respectively. Sequences were used to infer community composition using VSEARCH and a custom reference database combining curated fungal and oomycete sequences. Comparisons of diversity and community composition were conducted in $\mathrm{R}$ using the vegan and metacoder packages. Organism lifestyle was inferred using the FUNGuild database. Few oomycetes were found and fungal communities were dominated by saprobes and mutualists. Nurseries that grew plants in containers and in-field had a significantly higher diversity of fungi than those that only grew plants in containers. Microbiome composition differed significantly among growth conditions and nurseries, but not among cultivars. This suggests that, among these cultivars of rhododendron, environment is important in structuring the root microbiome, but cultivar is not.

Keywords: microbiome, mycology, plant pathology, rhizosphere and phyllosphere, soil ecology
Given major advances in microbiome research, it might soon become possible to engineer the microbiome of plants to improve nutrient absorption and health. Plants influence the composition and function of their microbiome by selectively recruiting a subset of the microbes from the surrounding environment that tend to provide benefits to the host (Berendsen et al. 2012). Plant genotype can affect this process, influencing the composition of the microbiome (Bálint et al. 2013; Panke-Buisse et al. 2015; Wagner et al. 2016).

${ }^{\dagger}$ Corresponding author: N. J. Grünwald: nik.grunwald@ars.usda.gov

Funding: This project was supported by funds from USDA-Agricultural Research Service CRIS Project 2072-22000-039-00D, 2072-22000-041-03-S, and 207222000-043-00-D the USDA-ARS Floriculture Nursery Initiative, the USDA-ARS NW Center for Nursery Crops, and the Oregon Department of Agriculture/Oregon Association of Nurseries (ODA-OAN) research programs.

*The $e$-Xtra logo stands for "electronic extra" and indicates that supplementary materials are published online.

The author(s) declare no conflict of interest.

This article is in the public domain and not copyrightable. It may be freely reprinted with customary crediting of the source. The American Phytopathological Society, 2020 .
Different cultivars of maize are known to respond differently to inoculation with the nitrogen-fixing bacteria Azospirillum; in some cultivars, addition of Azospirillum is equivalent to $100 \mathrm{~kg} \mathrm{ha}^{-1}$ of nitrogen, whereas other cultivars are unaffected (De Salamone et al. 1996). Different cultivars of wheat and grape have been observed to harbor distinct microbiomes (Bokulich et al. 2014; Sapkota et al. 2015). For fermentation substrates like grapes, the microbiome has additional relevance due to its effects on the sensory qualities of the finished product (Swiegers et al. 2005). Common garden experiments of wild plants also suggest that the fungal microbiome differs among genotypes of the same species (Bálint et al. 2013; Wagner et al. 2016). There is evidence that microbiome differences in natural stands of European beech correlate more with genotypic differences than with geographical distance (Cordier et al. 2012). Agricultural management practices have a major influence on the plant environment, which determines which microbes can be recruited and which pathogens will be present. For example, how a nursery recycles irrigation water could influence the community of oomycete pathogens (Redekar et al. 2019). Given a mechanistic understanding of the factors required to assemble a microbiome and achieve certain functions, one can envision a future where direct management of the plant microbiome can improve crop production. 
However, before a microbiome can be managed it has to be well characterized including how different hosts, cultivars, and production conditions can affect the microbiome.

High-throughput sequencing allows for rapid, affordable, and comprehensive characterization of the diversity found in microbial communities compared with sequencing by cloning or culturing ( $\mathrm{Ji}$ et al. 2013). For example, obligate symbionts and pathogens that have important implications for agriculture are difficult to culture and are therefore less likely to be detected by traditional culturebased microbial surveys (Yarza et al. 2014). New techniques, such as metabarcoding (i.e., amplicon metagenomics) and shotgun metagenomics, rely only on sequencing mixtures of PCR products or raw genomic DNA derived from environmental samples of complex communities, such as soil, and are therefore less biased by organismal lifestyle. Metabarcoding is a particularly powerful technique that involves extracting DNA from complex samples, amplifying a common barcode gene with PCR, and sequencing amplicons using high-throughput sequencing (Taberlet et al. 2012). Sequences can then be used to estimate community diversity and compared with reference databases to estimate community composition (Cole et al. 2008). However, metabarcoding also has its own set of biases, such as differential PCR efficiency and limited taxonomic resolution (Nichols et al. 2018). Recently, there have been attempts to use metabarcoding to characterize the communities and the distribution of pathogenic organisms, such as Phytophthora spp. in agricultural settings (Prigigallo et al. 2016; Riddell et al. 2019).

Rhododendron is a major ornamental crop in the Pacific Northwest and is known to host both mycorrhizal symbionts and plant pathogens (Farr et al. 1996; Knaus et al. 2015; Parke and Grünwald 2012; Parke et al. 2014). The nursery and greenhouse industry is a leading agricultural sector in the Pacific Northwest, with gross sales in Oregon of \$948 million in 2017 and rhododendrons are one of the leading ornamental plants sold (Losh 2017). Plants in the family Ericaceae, including Rhododendron, are known to form a distinct type of mutualism with fungi known as ericoid mycorrhizae. Ericoid mycorrhizae are known to aid their host in nutrient absorption and survival in poor and polluted soils (Cairney and Mehrag 2003). Rhododendrons in nurseries are also known to be vectors of the sudden death pathogen Phytophthora ramorum (Grünwald et al. 2008; Werres et al. 2001) and other oomycetes such as Phytophthora plurivora (Weiland et al. 2018). The presence of well-known mutualists and multiple pathogens combined with its economic importance make Rhododendron a good system to study the effects of management and cultivar on phytobiome composition (Jones and Benson 2001).

Root pathogens and symbionts described on rhododendron include both fungi and oomycetes. Oomycete pathogens generally cause root rot or damping off. Commonly found oomycetes on Rhododendron include Phytophthora plurivora, Phytophthora cinnamomi, and Pythium cryptoirregulare (Weiland et al. 2018). Fungal pathogens include Cylindrocladium scoparium, Cylindrocladium theae, Rhizoctonia solani, Armillaria mellea, and Thielaviopsis basicola (Dreistadt 2001; Jones and Benson 2001). Common ericoid mycorrhizal fungi isolated from ericaceous plants include ascomycetes such as Rhizoscyphus ericae, Oidiodendron maius, and dark septate endophytes, such as Phialocephala fortinii. Some basidiomycetes also occur, including Clavaria and members of the order Sebacinales (Dighton and Coleman 1992; Vohník and Albrechtová 2011; Vohník et al. 2005).

The goal of this study is to characterize the fungal and oomycete root microbiome of Rhododendron in Oregon nurseries and determine what factors might influence its composition. Therefore, we evaluated the relative importance of host genotype, environment, and management practices on structuring Rhododendron microbiomes in the rhizosphere using high-throughput sequencing. Specifically, we used metabarcoding to survey fungal and oomycete rhizosphere communities from three cultivars in four nurseries. We tested the hypothesis that microbiomes would differ among cultivars, nurseries, and production systems (container versus fieldgrown). We also expected to detect well-known Rhododendron pathogens, such as Phytophthora cinnamomi or Phytophthora plurivora, and well-known Rhododendron symbionts, such as Rhizoscyphus ericae or Phialocephala fortinii (Jones and Benson 2001; Knaus et al. 2015; Parke et al. 2014; Weiland et al. 2018). Our work provides novel insights into the makeup of oomycete and fungal communities in Rhododendron roots and is one of the few studies to apply Illumina sequencing to oomycete metabarcoding.

\section{MATERIALS AND METHODS}

Sample collection. The rhizosphere of Rhododendron was sampled to determine the effect of nursery, production system (container versus field-grown plants), and cultivar. Plants that appeared healthy were sampled in four nurseries from three cultivars in the Willamette Valley, Oregon, United States during May 2014. The nurseries varied in size and management practices. Nurseries A and B grew plants in both field and container systems while nurseries $\mathrm{C}$ and $\mathrm{D}$ grew plants only in containers. Both fieldgrown and container-grown plants were sampled. Rhododendron cultivars Nova Zembla (RHS 58), Roseum Elegans (RHS 58), and PJM (ARS874) were sampled in all nurseries and in both growing conditions. Five plants were sampled at random from each combination of nursery, cultivar, and production system (i.e., fieldgrown versus container-grown). Two nurseries only grew the selected cultivars in containers, so field-grown plants were only sampled from the other two nurseries. Each sample consisted of four equally-sized subsamples, each roughly $50 \mathrm{~cm}^{3}$, taken from opposite sides of the root ball. Root balls were sampled by hand using sterile gloves and transported to the lab on ice. In the case of fieldgrown plants, a hand trowel was used to expose the root ball on four sides and this trowel was sterilized between plants by rinsing in distilled water and $10 \%$ bleach.

Sample processing. Root ball samples were broken apart by hand using sterile gloves and excess dirt or potting media was shaken off to obtain rhizosphere samples. Gloves were changed between samples to avoid cross-contamination. Each frozen rhizosphere sample was ground by hand using a clean mortar and pestle with liquid nitrogen. Mortars and pestles were autoclaved for $1 \mathrm{~h}$ and soaked in $10 \%$ bleach for at least $4 \mathrm{~h}$ between uses (Prince and Andrus 1992). Ground rhizosphere samples were stored at $-80^{\circ} \mathrm{C}$ in prechilled Falcon tubes (Corning, MA) until DNA extraction of approximately $150 \mathrm{mg}$ of the sample using the Fast DNA Spin Kit (MP Biomedicals, Santa Ana, CA). The samples were not allowed to thaw at any time during this process.

PCR. We characterized both fungal and oomycete diversity using two internal transcribed spacer 1 (ITS1) primer pairs specific to each group. The fungal PCR used primers ITS1F (5' TCGTCGGCAGCGTCAGATGTGTATAAGAGACAGNCAAAC TTGGTCATTTAGAGGAAGTAA 3') and ITS2 (5' GTCTCGT GGGCTCGGAGATGTGTATAAGAGACAGGCTGCGTTCTTC ATCGATGC 3') (White et al. 1990). The underlined sequences are the Illumina adapters and the italic sequence is a spacer added to increase the annealing temperature to what is recommended in the Illumina $16 \mathrm{~S}$ sample preparation guide (Illumina Inc., San Diego, CA). The spacer was designed to be complementary to fungal DNA based on alignments of the primer to a random selection of sequences downloaded from GenBank. Each reaction consisted of 
$1 \times$ PCR buffer, $0.2 \mathrm{mM}$ dNTP mixture, $1 \mu \mathrm{M}$ of each primer, $0.15 \mu$ l of GeneScript Taq polymerase (GenScript, Piscataway, NJ), and $2 \mu \mathrm{l}$ of template DNA extract in a total volume of $15 \mu \mathrm{l}$. The thermocycler profile was $3 \mathrm{~min}$ at $94^{\circ} \mathrm{C}$, followed by 30 cycles of $30 \mathrm{~s}$ at $94^{\circ} \mathrm{C}, 45 \mathrm{~s}$ at $60^{\circ} \mathrm{C}$, and $1 \mathrm{~min}$ at $72^{\circ} \mathrm{C}$ with a final elongation for $7 \mathrm{~min}$ at $72^{\circ} \mathrm{C}$. The oomycete PCR was seminested and used ITS6 (GAAGGTGAAGTCGTAACAAGG) and ITS4 (TCCTCCGCTTATTGATATGC) without the MiSeq adapters followed by ITS6 (TCGTCGGCAGCGTCAGATGTGTATAA GAGACAGKGAAGGTGAAGTCGTAACAAGG) and ITS7 (GT CTCGTGGGCTCGGAGATGTGTATAAGAGACAGAGCGTTC TTCATCGATGTGC) with the MiSeq adapters (Sapkota and Nicolaisen 2015). The reactions for the first PCR consisted of $1 \times$ PCR buffer, $1.5 \mathrm{mM} \mathrm{MgCl}_{2}, 0.2 \mathrm{mM}$ dNTP mixture, $0.2 \mu \mathrm{M}$ of each primer, 0.04 units Platinum Taq polymerase (ThermoFisher Scientific, Waltham, MA), and $7.5 \mu$ l of template DNA extract in a total volume of $15 \mu \mathrm{l}$. The thermocycler profile was $2 \mathrm{~min}$ at $94^{\circ} \mathrm{C}$, followed by 25 cycles of $30 \mathrm{~s}$ at $94^{\circ} \mathrm{C}, 30 \mathrm{~s}$ at $60^{\circ} \mathrm{C}$, and $1 \mathrm{~min}$ at $72^{\circ} \mathrm{C}$ with a final elongation for $2 \mathrm{~min}$ at $72^{\circ} \mathrm{C}$. The second PCR had the same reaction composition and thermocycler profile, except that $1.5 \mu \mathrm{l}$ of a 1:10 dilution of the first PCR was used as the template.

Sequencing. The pooled oomycete and fungal libraries were sequenced on the Illumina MiSeq (Illumina) at the Center for Genome Research and Biocomputing (CGRB) at Oregon State University. Fungal and oomycete PCR products were mixed in equal volumes and used by the CGRB Core Lab to create sequencing libraries. In brief, the mixture of PCR products was cleaned with AMPure XP beads (Beckman Coulter, Brea, CA). Sample indexes were added using the Illumina Nextera XT kit and cleaned again with AMPure XP beads. The samples were then quantified using an Agilent Bioanalyzer (Agilent, Palo Alto, CA), diluted to the same concentration, and pooled. A total of $25 \% \mathrm{PhiX}$ was added to the pooled samples to correct for low diversity sequence bias. This library was then run on the CGRB's Illumina MiSeq using 250 bp paired-end sequencing.

Data analysis. An abundance matrix of operational taxonomic units (OTUs) versus samples was generated in order to compare the diversity and composition of the different cultivars, nurseries, and management practices. Primers and low-quality sequences were removed with cutadapt (Martin 2011). Any sequences with greater than $10 \%$ mismatch to the primers or more than two "N" ambiguity codes were filtered out. All sequences from the ends of each read that had a phred score of less than 20 were removed. VSEARCH (Rognes et al. 2016) was then used to merge forward and reverse reads. Pairs with less than 15 bp overlap or more than three mismatches were filtered out. Unique reads were found using the derep_fulllength command and singletons were filtered out. Predicted chimeric sequences were filtered out using the uchime_denovo command. The remaining sequences were then clustered into OTUs using the cluster_size command at 99 and $97 \%$ to approximate species-scale differences for oomycetes and fungi respectively. Finally, the usearch_global command was used to assign taxonomic classifications to OTUs by comparing them to a custom reference database composed of the UNITE database (Koljalg et al. 2005) for fungi, and Phytophthora-ID (Grünwald et al. 2011), Phytophthora-DB (Park et al. 2008), and the sequences from Robideau et al. (2011) for oomycetes. OTUs with less than 10 reads were filtered out. The taxonomy assigned to OTUs was used to infer organism lifestyle using FUNGuild (Nguyen et al. 2016). The FUNGuild results presented are those for OTUs that had at least a 97\% identity with the reference sequence supplying the taxonomy and that were considered "Probable" or "Highly probably" by FUNGuild.
The diversity of communities was compared with alpha (diversity within a sample) and beta (the compositional dissimilarity between two samples) diversity statistics and ordination techniques using the $R$ packages vegan (Dixon 2003), taxa (Foster et al. 2018), and metacoder (Foster et al. 2017). The inverse Simpson index was calculated for each sample as a measure of alpha diversity and the Bray-Curtis index was calculated for each pair of samples as a measure of beta diversity. Differences in alpha diversity among factors were determined using a Tukey's honest significant difference (HSD) test following analysis of variance (ANOVA). Differences in beta diversity were visualized using nonmetric multidimensional scaling (NMDS) using the metaMDS function from vegan (Kruskal 1964). Permutational multivariate analysis of variance (PERMANOVA), as implemented by the adonis function in the vegan package, was used to test which factors (cultivars, nurseries, and management practices) might be important for explaining differences in beta diversity (Anderson 2001). PERMANOVA is a nonparametric approach allowing partitioning of variance among factors, analogous to a factorial ANOVA. All factors and interactions were included in the model.

To test for taxa with differential abundance between factors, nonparametric Wilcoxon rank-sum tests (Mann and Whitney 1947) with a false discovery rate (FDR) correction for multiple tests were performed on the median read proportions for each taxon, at all taxonomic ranks. The results were visualized with differential heat trees using metacoder. For experimental factors that had more than two types (i.e., cultivar and nursery), differential abundance tests were conducted for each pairwise combination of types.

Data availability. All supplementary materials including $R$ scripts to reproduce the analysis and figures, FASTQ files, and the OTU abundance matrix were deposited at Open Science Framework (Foster and Grünwald 2019). The raw MiSeq sequences are also deposited in NCBI's Sequence Read Archive (BioProject PRJNA561631).

\section{RESULTS}

Sequencing. Raw reads were filtered and grouped into OTUs to simulate species-level differences. After processing the raw sequences with VSEARCH, a total of 3,120,565 reads were assigned to OTUs. At the primer removal step, approximately $6.3 \%$ of the reads were derived from the oomycete primers and $93.7 \%$ of the reads were derived from the fungal primers. After quality filtering, $3.6 \%$ of the reads were assigned to oomycetes and $96.4 \%$ of the reads were assigned to fungi. The number of raw reads per sample ranged from 8,869 to 82,015 . There were 1,915 OTUs in the raw data and 731 remaining after removing OTUs with fewer than 10 reads. The number of OTUs per sample ranged from 68 to 259 for raw counts and from 29 to 98 for filtered counts.

Alpha diversity. Differences in alpha diversity (i.e., the diversity within a sample) were determined using ANOVA followed by a Turkey's HSD test. Overall, differences in alpha diversity among factors were small or not significant (Fig. 1). There were minor, but significant, differences in diversity among the three cultivars. Nursery B had significantly higher alpha diversity than the others. Although there was no difference in alpha diversity between container-grown and field-grown plants, the species diversity of container-grown plants in nurseries that also grew plants in-field was greater than from container-grown plants in nurseries that only grew rhododendrons in containers $(P<0.05)$. The same analyses were done at the OTU and genus levels with similar results (Supplementary Figs. S1 to S3).

Beta diversity. Differences in rhizosphere community composition correlated with differences in nursery and production system, 
but not with differences in cultivar. NMDS revealed distinct communities associated with each combination of production system and nursery when using two (Fig. 2) or three dimensions (Supplementary Fig. S4). Production systems (e.g., container versus field-grown) separated communities based on axis NMDS1, whereas axis NMDS2 separated nurseries (Fig. 2). There was little, if any, clustering associated with cultivar. PERMANOVA supported the NMDS results, showing highly significant associations between community similarity and production system $\left(R^{2}=0.149\right.$; $P<0.001)$ or nursery $\left(R^{2}=0.234 ; P<0.001\right)$ (Table 1$)$. Cultivar was also significantly correlated, but the effect size was small $\left(R^{2}=0.025 ; P=0.001\right)$. The same analysis on other levels of the

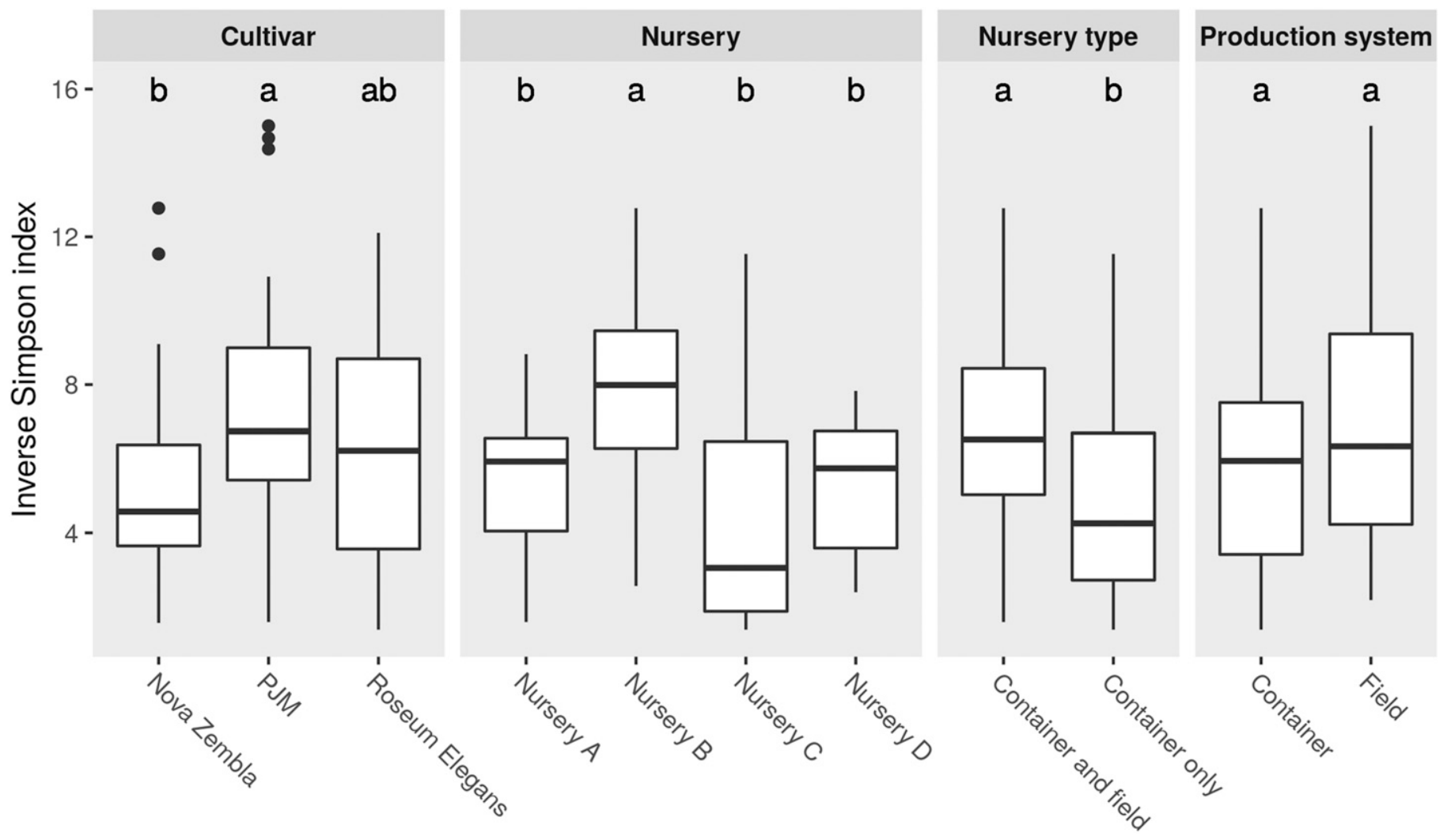

Fig. 1. Alpha diversity of the combined fungal and oomycete species in the Rhododendron rhizosphere in different cultivars (Nova Zembla, PJM, and Roseum Elegans), nurseries (A, B, C, and D), nursery types (plant grown in containers and field soil versus nurseries growing only in container soil), and production systems (container versus field-grown). Letters represent significantly different distributions as determined by analysis of variance followed by a Tukey's honest significant difference test.

A Production system

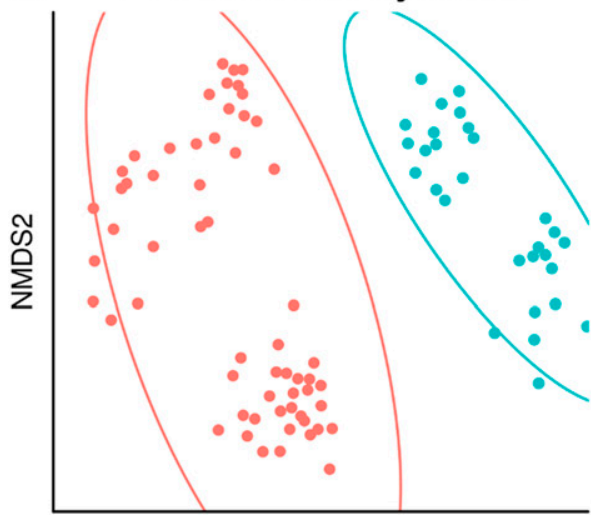

NMDS1
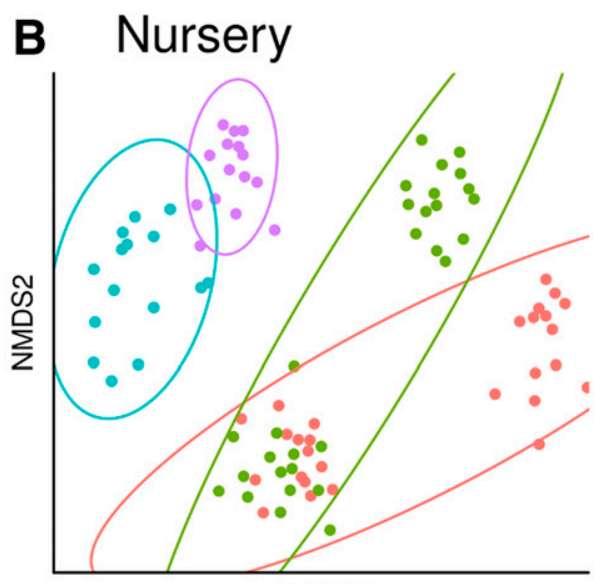

NMDS1
C Cultivar

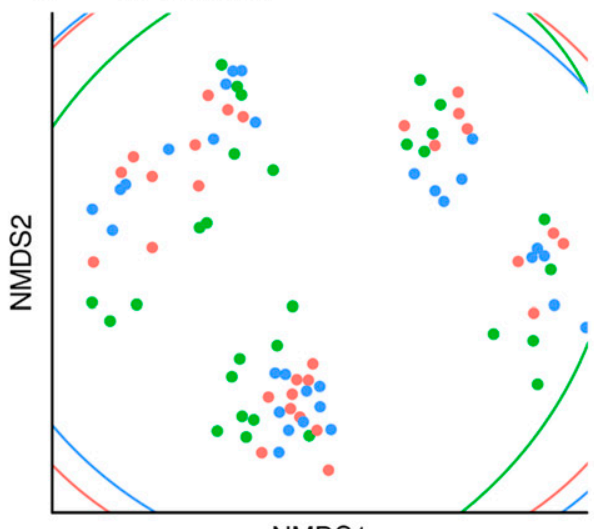

NMDS1

$\rightarrow$ Container $\rightarrow$ Field

$\rightarrow A \rightarrow B \rightarrow C \rightarrow D$

$\rightarrow$ Nova Zembla $\rightarrow$ PJM $\rightarrow$ Roseum Elegans

Fig. 2. Two-dimensional nonmetric multidimensional scaling of Bray-Curtis distances between samples based on operational taxonomic unit relative abundance for both oomycetes and fungi. Ellipses represent $95 \%$ confidence intervals, assuming a multivariate t-distribution. Samples colored by A, container versus field-grown Rhododendron, $\mathbf{B}$, the four nurseries sampled, and $\mathbf{C}$, the three Rhododendron cultivars sampled. 
taxonomic hierarchy (e.g., OTU, species, genus, and family) showed similar results (Supplementary Fig. S5).

Only the comparison between container and field-grown samples indicated significant differences in median read abundance for numerous taxa, as determined by Wilcoxon rank sum tests followed by a false discovery rate correction (Fig. 3 and Supplementary Fig. S6). Taxa with a greater proportion of reads assigned to them in field-grown samples than container-grown samples include: Phialocephala fortinii, Cladophialophora chaetospira, Galerina atkinsoniana, Solicoccozyma terrea, and Trichoderma crassum. Taxa with a higher read abundance in container-grown samples than in field-grown samples include: Coniochaeta lignicola, Lecythophora fasciculata, Pleurostoma richardsiae, Sporothrix lignivora, and Exophiala hetermorpha. No significant differences between experimental factors were observed for any oomycete taxa, probably due to the infrequency of detecting individual oomycete taxa relative to the number of samples for each factor.

Organismal diversity. Saprobes and beneficial fungi dominated the fungal and oomycete communities in rhododendron roots, according to FUNGuild results. Most sequence reads were assigned to saprobes and beneficial organisms (Supplementary Fig. S7). Pathogens were much less common than either saprobic or beneficial fungi. The three most common putative mutualists were OTUs matching reference sequences ( $\geq 99.5 \%$ identity) for Lecythophora fasciculata, Trichoderma pubescens, and Phialocephala fortinii, appearing in 74, 68, and 53\% of samples, respectively. The 10 most common saprobes occurred individually in 38 to $18 \%$ of samples and included OTUs that matched reference sequences $(\geq 99.5 \%$ identity) of Xenopolyscytalum pinea, Humicola grisea, Cladophialophora chaetospira, Scytalidium lignicola, and Trichocladium opacum. We also found taxa typically associated with ericaceous plants to be common, including taxa in the genera Rhizoscyphus, Meliniomyces, Oidiodendron, Pezoloma, Hymenoscyphus, Phialocephala, and the order Sebacinales (Fig. 4 and Supplementary Fig. S7). Trichoderma (some with purported biocontrol properties) and the saprophytic genera Galerina and Mortierella were also common and diverse.

Putative plant pathogens were generally much less common than saprobes or mutualists. Some potential fungal pathogens found include Pestalotiopsis unicolor, Pestalotiopsis rhododendri, and Ophiostoma bragantinum, which were found in 23, 10, and $8 \%$ of samples, respectively. The genus Microbotryum was also found. There were much fewer OTUs assigned to oomycetes than fungi

TABLE 1

Results of permutational multivariate analysis of variance (PERMANOVA) of Bray-Curtis distances between samples ${ }^{a}$

\begin{tabular}{llc}
\hline Factor & $R^{2}$ & $P$ \\
\hline Cultivar & 0.025 & 0.0012 \\
\hline Production system & 0.149 & 0.0001 \\
\hline Nursery & 0.234 & 0.0001 \\
\hline Cultivar $\times$ production system & 0.025 & 0.0007 \\
\hline Cultivar $\times$ nursery & 0.076 & 0.0001 \\
\hline Production system $\times$ nursery & 0.045 & 0.0001 \\
\hline Cultivar $\times$ production system $\times$ nursery & 0.028 & 0.0003 \\
\hline Residuals & 0.418 & - \\
\hline $\begin{array}{l}\text { a PERMANOVA was conducted to test for correlations between } \\
\text { community similarity and combinations of cultivar, production system } \\
\text { (field versus container), and nursery factors. A total of 9,999 } \\
\text { permutations were performed. }\end{array}$ &
\end{tabular}

and these OTUs occurred in much fewer samples than the common fungal OTUs. Due to the nature of oomycete ITS1 sequences, OTUs that differ by more than $1 \%$ in sequence identity from their closest reference sequences are very likely different species than the one assigned and even exact matches do not always resolve individual species (Redekar et al. 2019). The reference sequences that were matched well ( $>99 \%$ identity) by the most common oomycete OTUs include Pythium irregulare, Pythium sylvaticum, Phytophthora cactorum, Phytophthora citricola, and Phytophthora infestans. These putative pathogens appeared in 11 to $2 \%$ of samples. Less frequently, sequences matching Pythium macrosporum and Pythium dissotocum were found. Other OTUs found had no close match to a reference sequence or occurred in only one sample. These likely represent either technical error or species not in the reference database.

\section{DISCUSSION}

The environment of plants has a strong influence on the composition, and therefore function, of the microbiome (Bonito et al. 2014; Wagner et al. 2016). The plants sampled in this study differed by nursery and production system (container versus fieldgrown), both of which constitute different environments that are expected to change the composition of associated microbiomes. Of all the factors tested, production system and nursery were the two best predictors of differences in the root microbiome according to NMDS (Fig. 2) and PERMANOVA (Table 1). The effect of production system is likely due in part to the difference in growing media: container-grown plants were grown in nearly $100 \%$ Douglas fir bark chips whereas field-grown plants were grown in soil. Surprisingly, there was no significant difference in alpha diversity between the two types of production systems (Fig. 1). We expected that field soil would support a more diverse community of fungi than a potting mix largely composed of bark and that would be reflected in the diversity of the rhizosphere community. However, it could be that rhododendrons select a subset of the bulk soil community, as happens in other plants (Uroz et al. 2010), and that both environments have more diversity than is selected, even if the potting media is less diverse. Since we did not analyze bulk soil samples, we cannot confirm this. It could also be that the soil in the fields had relatively little organic matter and thus supported less saprotrophic diversity than the potting mix that was almost entirely organic matter. The composition of rhizosphere communities also varied among nurseries (Fig. 2), even though production system was the dominant effect. For example, the container-grown plants from nurseries $\mathrm{A}$ and $\mathrm{B}$ clustered together in NMDS ordination, as to a lesser degree did the field-grown plants. This suggests that there could be microbiomes characteristic of container-grown and field-grown plants regardless of where they are grown, even though the location also has an effect. If this is true, it would mean that cultivation practices can have predictable effects on the microbiome of Rhododendron and that there is potential for optimizing these practices to maximize the benefits received from the microbiome. However, a study of a much greater number of nurseries, representative of a larger geographical area and greater diversity of cultivation practices, would be needed to verify that this result applies to nursery-grown Rhododendron in general.

In many agricultural plant species, slight genotypic differences influencing interactions with the plant's microbiome can have a large impact on plant productivity (De Salamone et al. 1996). Surprisingly, we observed little, if any, differences between the microbiome compositions of the three cultivars of Rhododendron sampled (Fig. 2). This suggests that either the cultivars we selected 
are not very distinct genotypically or that their differences are not relevant for structuring the microbiome under the conditions sampled. If the microbiomes of other cultivars of Rhododendron are similarly indistinct, attempts at breeding for beneficial microbial communities will likely be ineffective. A study of the perennial herb Boechera stricta revealed an association between genotype and leaf microbiome but no association between genotype and root microbiome, although a genotype by environment interaction was significant (Wagner et al. 2016). In our results, interactions between environmental factors (production system and nursery) and cultivar were also more significant than cultivar alone according to PERMANOVA, but the effect size was small relative to the environmental factors alone (Table 1). In addition, the relative effects of environment and genotype can be different for bacteria and fungi (Bonito et al. 2014), so it is possible that bacterial communities, which we did not characterize, have a stronger association with genotype.
Saprobes and symbionts are the most ubiquitous organisms observed in the Rhododendron rhizosphere. Some of the most commonly observed organisms, Humicola grisea and Cladophialophora chaetospira, have been isolated from Rhododendron in other studies and Trichoderma opacum has been isolated from other ericaceous plants (Bruzone et al. 2017; Kowalik et al. 2015; Vanó et al. 2011). Cladophialophora chaetospira has been observed to form intracellular structures in root cells of Rhododendron, similar to ericoid mycorrhizae (Vanó et al. 2011). Scytalidium lignicola is an anamorphic ascomycete generally found in wood or compost and is related to pathogens of Citrus and Manihot (Büttner et al. 2018). The common ericoid mycorrhizal fungus Pezoloma ericae (aka Hymenoscyphus ericae) was found often (Vrålstad et al. 2002). Ericoid mycorrhizal fungi, such as Pezoloma ericae, have been previously reported on Rhododendron and as root endosymbionts shown to aid in the breakdown of organic debris, releasing mineral

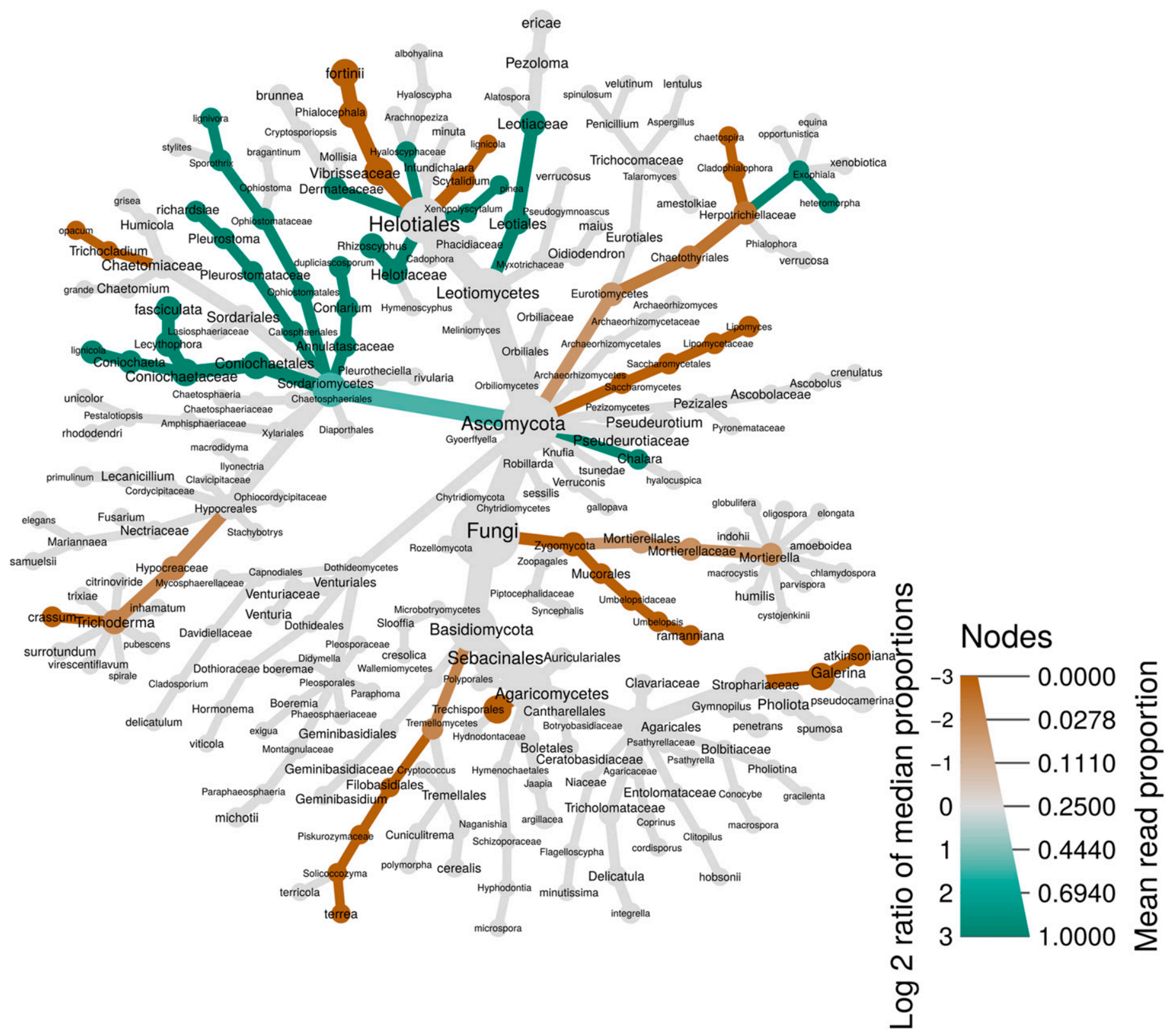

Fig. 3. Differential heat tree (i.e., taxonomic tree) showing significant differences in median read proportion between fungal operational taxonomic units found in the rhizosphere from container-grown (green) versus field-grown (brown) rhododendrons. Significance was determined using Wilcox rank-sum tests with a false discovery rate correction for multiple comparisons. Only taxa that appear in at least five samples are shown. 
forms of nutrients that are available to the plant host (Smith and Read 2010). The dark septate endophyte Phialocephala fortinii was also common and is known to aid in the breakdown of organic compounds, potentially leading to increased growth (Surono and Narisawa 2017). The commonly found genus Trichoderma is known to contain many plant rhizosphere symbionts with biocontrol applications (Harman 2006). The frequent occurrence of individual beneficial symbionts and saprobes combined with the negative results of differential taxon abundance analysis among nurseries and cultivar suggest that there might be a subset of the fungal community that is typical of rhododendron.

Plant pathogens were much less common than saprobes and mutualists. The most common pathogen found was Pestalotiopsis unicolor (99.6\% identity), which appeared in $23 \%$ of samples. The genus Pestalotiopsis contains a diverse group of anamorphic plant pathogens that causes a variety of diseases such as leaf spots, blights, and cankers in many agricultural hosts, including blueberry (Maharachchikumbura et al. 2014). An OTU similar to Pestalotiopsis rhododendri (99.1\% identity) was also observed in $9 \%$ of samples. Pestalotiopsis rhododendri was originally described on Rhododendron sinogrande in 2013 in China (Zhang et al. 2013). The only oomycete pathogen that was commonly predicted and had a high sequence similarity to its reference was an OTU matching Pythium irregulare, which occurred in $11 \%$ of samples. The next most common Pythium observed was Pythium sylvaticum, occurring in $3 \%$ of samples. Oddly, an OTU matching Phytophthora infestans was also found in $3 \%$ of samples. However, it should be noted that we only sequenced ITS1 and even with the entire ITS sequence, it is not always possible to differentiate oomycetes species, so even a $100 \%$ sequence match to a reference sequence does not necessarily imply that an OTU is from that species. In particular, Pythium irregulare has the same sequence as Pythium cryptoirregulare and Phytophthora infestans has the same sequence as Phytophthora andina, Phytophthora mirabilis, and Phytophthora ipomoeae in this region of the ITS (Redekar et al. 2019). The OTU matching Phytophthora infestans could also be from an undescribed species, considering that the known species sharing a sequence with Phytophthora infestans are not known to occur on

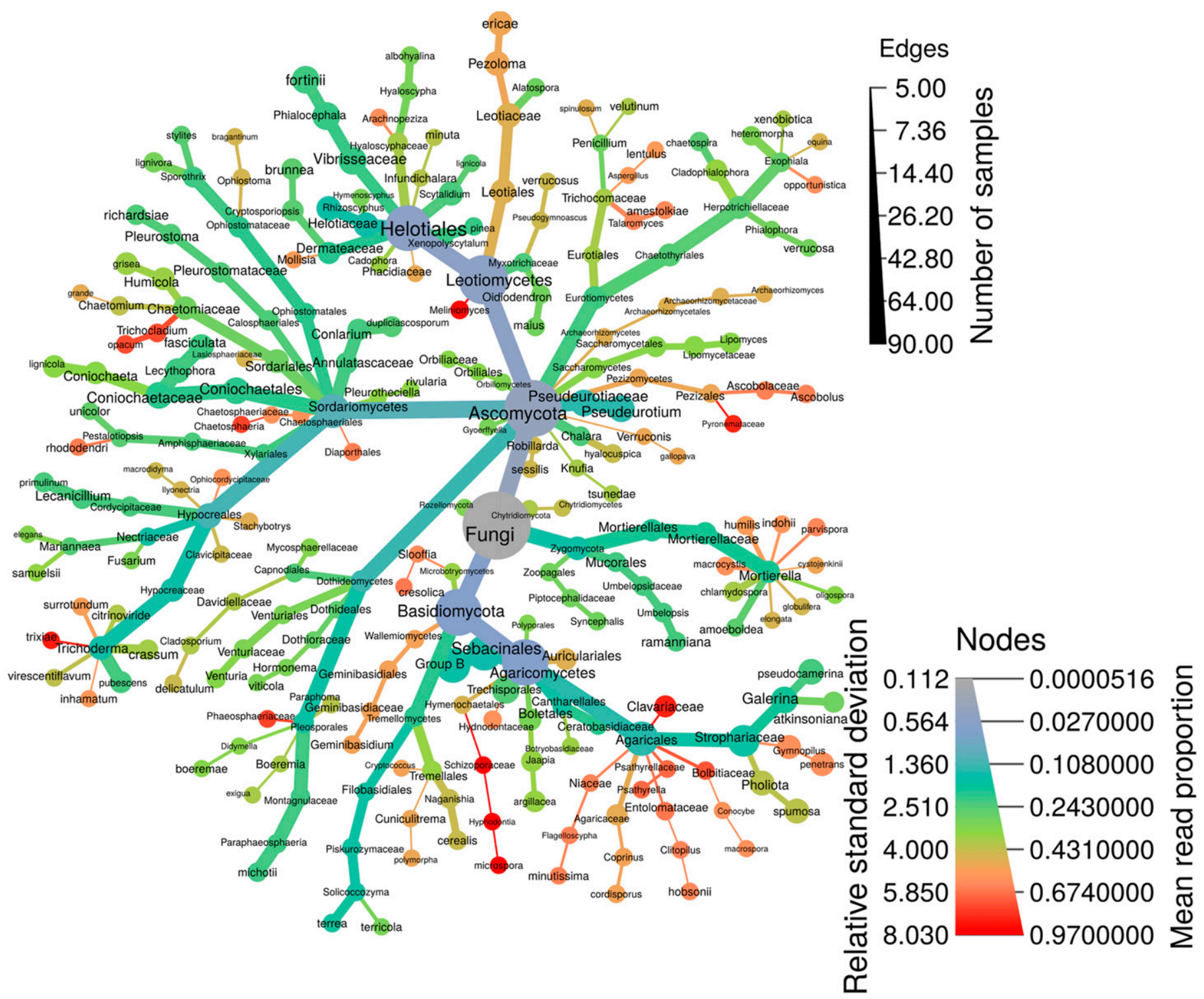

Fig. 4. A heat tree (i.e., taxonomic tree) of fungal taxa with unambiguous classifications found in at least five samples. Edge width is proportional to the number of samples a given taxon was found in. The color and size of nodes is the relative standard deviation of operational taxonomic unit read proportions and the mean read proportion, respectively. Cooler colors indicate less variation between samples and hotter colors indicate more. 
Rhododendron. The rare OTU classified as Phytophthora citricola could also be Phytophthora plurivora, which was found to be common in diseased rhododendrons in Oregon (Carleson et al. 2018). Notably, we did not detect some pathogens commonly found when sampling symptomatic tissue, such as Phytophthora syringae and Phytophthora citrophthora (Parke et al. 2014). We found a rare OTU in two samples that most closely matched Phytophthora cinnamomi with $98.9 \%$ sequence identity, but for the previously mentioned reasons, this level of similarity does not indicate that Phytophthora cinnamomi was actually present. We also found fewer Phytophthora species compared with some other oomycete metabarcoding studies, which find around 20 species total, albeit in diseased plants for a greater diversity of sites (Prigigallo et al. 2016; Riddell et al. 2019). The relative infrequency of pathogens and the different pathogens found compared with some previous research is probably due to sampling apparently healthy plants, whereas many studies target symptomatic plants (Weiland et al. 2018).

This study used high-throughput amplicon sequencing to characterize how the oomycete and fungal rhizobiome of rhododendrons in Oregon nurseries is structured by plant cultivar and environmental factors. The overall diversity of samples varied little between production system, nursery, and cultivar, although plants in nurseries that had both container and in-field production systems were significantly more diverse than those in nurseries that only grew plants in containers. The differences between the compositions of microbiome communities were correlated with production system and nursery, but not cultivar. Communities were dominated by saprobes and symbionts. This study provides novel insights into potential factors influencing the rhizosphere microbiome of rhododendrons in nurseries, and more generally, how plant genotype and environment impact the makeup of the rhizobiome of woody plants.

\section{ACKNOWLEDGMENTS}

We thank Brian Beck, Karan Fairchild, Meg Larsen, and Caroline Press for technical and logistical support. We also want to thank the developers of the open source software we used to conduct our analysis for providing a free and reproducible way to conduct research.

\section{LITERATURE CITED}

Anderson, M. J. 2001. A new method for non-parametric multivariate analysis of variance. Austral Ecol. 26:32-46.

Bálint, M., Tiffin, P., Hallström, B., O’Hara, R. B., Olson, M. S., Fankhauser, J. D., Piepenbring, M., and Schmitt, I. 2013. Host genotype shapes the foliar fungal microbiome of balsam poplar (Populus balsamifera). PLoS One 8:e53987.

Berendsen, R. L., Corne, M. J. P., and Bakker, P. A. H. M. 2012. The rhizosphere microbiome and plant health. Trends Plant Sci. 17:478-486.

Bokulich, N. A., Thorngate, J. H., Richardson, P. M., and Mills, D. A. 2014. Microbial biogeography of wine grapes is conditioned by cultivar, vintage, and climate. Proc. Natl. Acad. Sci. USA 111:E139-E148.

Bonito, G., Reynolds, H., Robeson, M. S., II, Nelson, J., Hodkinson, B. P., Tuskan, G., Schadt, C. W., and Vilgalys, R. 2014. Plant host and soil origin influence fungal and bacterial assemblages in the roots of woody plants. Mol. Ecol. 23:3356-3370.

Bruzone, M. C., Fehrer, J., Fontenla, S. B., and Vohnik, M. 2017. First record of Rhizoscyphus ericae in Southern hemisphere's ericaceae. Mycorrhiza 27:147-163.

Büttner, E., Gebauer, A. M., Hofrichter, M., Liers, C., and Kellner, H. 2018. Draft genome sequence of Scytalidium lignicola DSM 105466, a ubiquitous saprotrophic fungus. Microbiol. Resour. Announc. 7:e01208-e01218.

Cairney, J. W. G., and Mehrag, A. A. 2003. Ericoid mycorrhiza: A partnership that exploits harsh edaphic conditions. Eur. J. Soil Sci. 54:735-740.

Carleson, N. C., Fieland, V., Scagel, C. R., Weiland, J. E., and Grünwald, N. J. 2018. Population structure of Phytophthora plurivora on Rhododendron in Oregon nurseries. Plant Dis. 103:1923-1930.
Cole, J. R., Wang, Q., Cardenas, E., Fish, J., Chai, B., Farris, R. J., Kulam-SyedMohideen, A. S., McGarrell, D. M., Marsh, T., Garrity, G. M., and Tiedje, J. M. 2008. The Ribosomal Database Project: Improved alignments and new tools for rRNA analysis. Nucleic Acids Res. 37:D141-D145.

Cordier, T., Robin, C., Capdevielle, X., Desprez-Loustau, M. L., and Vacher, C. 2012. Spatial variability of phyllosphere fungal assemblages: Genetic distance predominates over geographic distance in a European beech stand (Fagus sylvatica). Fungal Ecol. 5:509-520.

De Salamone, I. E. G., Döbereiner, J., Urquiaga, S., and Boddey, R. M. 1996. Biological nitrogen fixation in Azospirillum strain-maize genotype associations as evaluated by the $15 \mathrm{~N}$ isotope dilution technique. Biol. Fertil. Soils 23:249-256.

Dighton, J., and Coleman, D. C. 1992. Phosphorus relations of roots and mycorrhizas of Rhododendron maximum L. in the southern Appalachians, North Carolina. Mycorrhiza 1:175-184.

Dixon, P. 2003. VEGAN, a package of R functions for community ecology. J. Veg. Sci. 14:927-930.

Dreistadt, S. H. 2001. Integrated Pest Management for Floriculture and Nurseries, Vol. 3402. UCANR Publications, Oakland, CA.

Farr, D., Esteban, H., and Palm, M. 1996. Fungi on Rhododendron. Parkway Publishers, Boone, NC.

Foster, Z. S. L., Chamberlain, S., and Grünwald, N. J. 2018. Taxa: An R package implementing data standards and methods for manipulation of taxonomic data. F1000 Res. 7:272.

Foster, Z. S. L., and Grünwald, N. J. 2019. Rhododendron microbiome. OSF. doi:10.17605/osf.io/KGPW3

Foster, Z. S. L., Sharpton, T. J., and Grünwald, N. J. 2017. Metacoder: An R package for visualization and manipulation of community taxonomic diversity data. PLoS Comp. Biol. 13:e1005404.

Grünwald, N. J., Goss, E. M., and Press, C. M. 2008. Phytophthora ramorum: A pathogen with a remarkably wide host-range causing sudden oak death on oaks and ramorum blight on woody ornamentals. Mol. Plant Pathol. 9:729-740.

Grünwald, N. J., Martin, F. N., Larsen, M. M., Sullivan, C. M., Press, C. M., Coffey, M. D., Hansen, M. D., Everett, M., and Parke, J. L. 2011. Phytophthora-ID.org: A sequence-based Phytophthora identification tool. Plant Dis. 95:337-342.

Harman, G. E. 2006. Overview of mechanisms and uses of Trichoderma spp. Phytopathology 96:190-194.

Ji, Y., Ashon, L., Pedley, S. M., Edwards, D. P., Tang, Y., Nakamura, A., Kitching, R., Dolman, P. M., Woodcock, P., Edwards, F. A., Larsen, T. H., Hsu, W. W., Benedick, S., Hamer, K. C., Wilcove, D. S., Bruce, C., Wang, X., Levi, T., Lott, M., Emerson, B. C., and Douglas, W. Y. 2013. Reliable, verifiable and efficient monitoring of biodiversity via metabarcoding. Ecol. Lett. 16:1245-1257.

Jones, R. K., and Benson, D. M. 2001. Diseases of Woody Ornamentals and Trees in Nurseries.American Phytopathological Society, St. Paul, MN.

Knaus, B. J., Fieland, V. J., Graham, K. A., and Grünwald, N. J. 2015. Diversity of foliar Phytophthora species on Rhododendron in Oregon nurseries. Plant Dis. 99:1326-1332.

Koljalg, U., Larsson, K., Abarenkov, K., Nilsson, R. H., Alexander, I. J., Eberhardt, U., Erland, S., Hoiland, K., Kjoller, R., Larsson, E., Pennanen, T., Sen, R., Taylor, A. F. S., Tedersoo, L., and Vralstad, T. 2005. UNITE: A database providing web-based methods for the molecular identification of ectomycorrhizal fungi. New Phytol. 166:1063-1068.

Kowalik, M., Kierpiec-Baran, B., and Duda-Franiak, K. 2015. Micromycetes colonizing and damaging leaves of evergreen rhododendron (Rhododendron L.) in nursery. Acta Agrobot. 68:179-185.

Kruskal, J. B. 1964. Non-metric multidimensional scaling: A numerical method. Psychometrika 29:115-129.

Losh, D. 2017. Oregon agriculture, facts and figures. Oregon Department of Agriculture. https://oregonfresh.net/education/ag-facts-figures/oregon-factsfigures/

Maharachchikumbura, S. S., Hyde, K. D., Groenewald, J. Z., Xu, J., and Crous, P. W. 2014. Pestalotiopsis revisited. Stud. Mycol. 79:121-186.

Mann, H. B., and Whitney, D. R. 1947. On a test of whether one of two random variables is stochastically larger than the other. Ann. Math. Stat. 18:50-60.

Martin, M. 2011. Cutadapt removes adapter sequences from high-throughput sequencing reads. EMBnet J. 17:10-12.

Surono, and Narisawa, K. 2017. The dark septate endophytic fungus Phialocephala fortinii is a potential decomposer of soil organic compounds and a promoter of Asparagus officinalis growth. Fungal Ecol. 28:1-10.

Nguyen, N. H., Song, Z., Bates, S. T., Branco, S., Tedersoo, L., Menke, J., Schilling, J. S., and Kennedy, P. G. 2016. FUNGuild: An open annotation tool 
for parsing fungal community datasets by ecological guild. Fungal Ecol. 20: 241-248.

Nichols, R. V., Vollmers, C., Newsom, L. A., Wang, Y., Heintzman, P. D., Leighton, M., Green, R. E., and Shapiro, B. 2018. Minimizing polymerase biases in metabarcoding. Mol. Ecol. Resour. 18:927-939.

Panke-Buisse, K., Poole, A. C., Goodrich, J. K., Ley, R. E., and Kao-Kniffin, J. 2015. Selection on soil microbiomes reveals reproducible impacts on plant function. ISME J. 9:980-989.

Park, J., Park, B., Veeraraghavan, N., Jung, K., Lee, Y. H., Blair, J. E., Geiser, D. M., Isard, S., Mansfield, M. A., Nikolaeva, E., and Park, S. Y. 2008.

Phytophthora database: A forensic database supporting the identification and monitoring of Phytophthora. Plant Dis. 92:966-972.

Parke, J. L., and Grünwald, N. J. 2012. A systems approach for management of pests and pathogens of nursery crops. Plant Dis. 96:1236-1244.

Parke, J. L., Knaus, B. J., Fieland, V. J., Lewis, C., and Grünwald, N. J. 2014. Phytophthora community structure analyses in Oregon nurseries inform systems approaches. Phytopathology 104:1052-1062.

Prigigallo, M. I., Abdelfattah, A., Cacciola, S. O., Faedda, R., Sanzani, S. M., Cooke, D. E. L., and Schena, L. 2016. Metabarcoding analysis of Phytophthora diversity using genus-specific primers and 454 pyrosequencing. Phytopathology 106:305-313.

Prince, A. M., and Andrus, L. 1992. PCR: How to kill unwanted DNA. Biotechniques 12:358-360.

Redekar, N. R., Eberhart, J. L., and Parke, J. L. 2019. Diversity of Phytophthora, Pythium, and Phytopythium species in recycled irrigation water in a container nursery. Phytobiomes J. 3:31-45.

Riddell, C. E., Frederickson-Matika, D., Armstrong, A. C., Elliot, M., Forster, J., Hedley, P. E., Morris, J., Thorpe, P., Cooke, D. E., Pritchard, L., Sharp, P. M., and Green, S. 2019. Metabarcoding reveals a high diversity of woody hostassociated Phytophthora spp. in soils at public gardens and amenity woodlands in Britain. PeerJ 7:e6931.

Robideau, G. P., De Cock, A. W., Coffey, M. D., Voglmayr, H., Brouwer, H., Bala, K., Chitty, D. W., Désaulniers, N., Eggertson, Q. A., and Gachon, C. M. 2011. DNA barcoding of oomycetes with cytochrome c oxidase subunit I and internal transcribed spacer. Mol. Ecol. Resour. 11:1002-1011.

Rognes, T., Flouri, T., Nichols, B., Quince, C., and Mahe, F. 2016. VSEARCH: A versatile open source tool for metagenomics. PeerJ 4:E2584.

Sapkota, R., Knorr, K., Jørgensen, L. N., O’Hanlon, K. A., and Nicolaisen, M. 2015. Host genotype is an important determinant of the cereal phyllosphere mycobiome. New Phytol. 207:1134-1144.

Sapkota, R., and Nicolaisen, M. 2015. An improved high throughput sequencing method for studying oomycete communities. J. Microbiol. Methods 110:33-39.

Smith, S. E., and Read, D. J. 2010. Mycorrhizal Symbiosis. Academic Press, Cambridge, MA.
Swiegers, J. H., Bartowsky, E. J., Henschke, P. A., and Pretorius, I. S. 2005. Yeast and bacterial modulation of wine aroma and flavour. Aust. J. Grape Wine Res. 11:139-173.

Taberlet, P., Coissac, E., Pompanon, F., Brochmann, C., and Willerslev, E. 2012. Towards next-generation biodiversity assessment using DNA metabarcoding. Mol. Ecol. 21:2045-2050.

Uroz, S., Buée, M., Murat, C., Frey-Klett, P., and Martin, F. 2010. Pyrosequencing reveals a contrasted bacterial diversity between oak rhizosphere and surrounding soil. Environ. Microbiol. Rep. 2:281-288.

Vanó, I., Sakamoto, K., and Inubushi, K. 2011. Phylogenetic relationships among non-pathogenic isolates of dark septate endophytes from Ericaceae plants. Hortic. Res. 65:41-47.

Vohník, M., and Albrechtová, J. 2011. The co-occurrence and morphological continuum between ericoid mycorrhiza and dark septate endophytes in roots of six European Rhododendron species. Folia Geobot. 46:373-386.

Vohník, M., Albrechtová, J., and Vosátka, M. 2005. The inoculation with Oidiodendron maius and Phialocephala fortinii alters phosphorus and nitrogen uptake, foliar $\mathrm{C}: \mathrm{N}$ ratio and root biomass distribution in Rhododendron cv. Azurro. Symbiosis 40:87-96.

Vrålstad, T., Schumacher, T., and Taylor, A. F. 2002. Mycorrhizal synthesis between fungal strains of the Hymenoscyphus ericae aggregate and potential ectomycorrhizal and ericoid hosts. New Phytol. 153:143-152.

Wagner, M. R., Lundberg, D. S., Tijana, G., Tringe, S. G., Dangl, J. L., and Mitchell-Olds, T. 2016. Host genotype and age shape the leaf and root microbiomes of a wild perennial plant. Nat. Commun. 7:12151.

Weiland, J. E., Scagel, C. F., Grünwald, N. J., Davis, E. A., and Beck, B. R. 2018. Variation in disease severity caused by Phytophthora cinnamomi, P. plurivora, and Pythium cryptoirregulare on two rhododendron cultivars. Plant Dis. 102:2560-2570.

Werres, S., Marwitz, R., In't Veld, W. A., De Cock, A. W., Bonants, P. J., De Weerdt, M., Themann, K., Ilieva, E., and Baayen, R. P. 2001. Phytophthora ramorum sp. nov., a new pathogen on Rhododendron and Viburnum. Mycol. Res. 105:1155-1165.

White, T.J., Bruns, T., Lee, S.J., and Taylor, J.W. 1990. Amplification and direct sequencing of fungal ribosomal RNA genes for phylogenetics. PCR Protocols: A Guide to Methods and Applications 18:315-22.

Yarza, P., Yilmaz, P., Pruesse, E., Glöckner, F. O., Ludwig, W., Schleifer, K., Whitman, W. B., Euzéby, J., Amann, R., and Rosselló-Móra, R. 2014. Uniting the classification of cultured and uncultured bacteria and archaea using 16S rRNA gene sequences. Nat. Rev. Microbiol. 12: 635-645.

Zhang, Y., Maharachchikumbura, S. S. N., Tian, Q., and Hyde, K. D. 2013. Pestalotiopsis species on ornamental plants in Yunnan Province, China. Sydowia 65:113-128. 